\title{
Comment on an article by Ahuja et al.
}

\author{
Satoshi Ideno $\cdot$ Noriko Miyazawa
}

Received: 30 May 2014 / Accepted: 4 June 2014/Published online: 6 July 2014

(C) Japanese Society of Anesthesiologists 2014

Keywords Aerodigestive foreign bodies - Difficult airway $\cdot$ Infant feeding tube

To the Editor:

The case reported by Ahuja et al. [1] entitled "Infant feeding tube as rescue endotracheal tube in an infant with an aerodigestive foreign body" is very interesting. They used an $8 \mathrm{Fr}$ infant feeding tube (IFT, outer diameter of $2.4 \mathrm{~mm}$ ) as a rescue endotracheal tube (ETT) for a 1-yearold boy undergoing a procedure for the retrieval of a small button battery, which resulted in avoidance of emergency tracheostomy. We agree that it is beneficial to use an alternative airway apparatus on a case-by-case basis for performing safe pediatric anesthesia.

We would like to know the details of the intraoperative respiratory management including the ventilator setting, $\mathrm{EtCO}_{2}$ waveform, and expiratory pressure. The author did not mention the inner diameter (ID) of the IFT. We assume that the IFT used was approximately $2.0 \mathrm{~mm}$ ID, if the estimated IFT wall thickness was approximately $0.2 \mathrm{~mm}$. According to Hagen-Poiseuille's law, airway resistance of an IFT would be 16 times as high as that of an ETT with an
ID of $4.0 \mathrm{~mm}$, which is generally said to be the ideal size for a healthy 1-year-old boy. High airway resistance could be a problem during the expiratory phase, causing hypercapnia and auto-positive end-expiratory pressure.

Airway complications could arise because of mechanical compression during endoscopic removal of the foreign bodies, even though ventilation was initially secured. As the author mentioned, it is important to make ready various types of equipment to facilitate intubation. In addition, we suggest that the preparation of emergency invasive airway access should be continued even after intubation in a case of compromised airway.

\section{Conflict of interest None.}

\section{Reference}

1. Ahuja V, Kazal S, Thapa D, Singh M, Bhutani M. Infant feeding tube as rescue endotracheal tube in an infant with an aerodigestive foreign body. J Anesth. 2014;28:315-6.

An answer to this letter to the editor is available at doi:10.1007/s00540-014-1876-9.

S. Ideno $(\bowtie) \cdot$ N. Miyazawa

Department of Anesthesiology, Tokyo Metropolitan Children's Medical Center, 2-8-29 Musashidai, Fuchu, Tokyo 183-8561, Japan

e-mail: doctor_idebon@yahoo.co.jp 